\title{
Postoperative Reversal of Complete (Monocular) Blindness in Skull Base Meningioma: Case Report
}

\author{
Joseph Bampoe, Paul Ranalli, Mark Bernstein
}

\begin{abstract}
Background: Meningiomas of the anterior cranial fossa frequently present with impaired visual function. Recognition of this entity in the differential diagnosis of painless, progressive, and asymmetric optic neuropathy is important since reversal of visual loss is possible given timely surgical excision of the tumour. Methods: A 76-year-old man presented with no perception of light in his right eye and a reduced visual acuity of 20/60 in his left eye with a markedly constricted visual field. His visual deterioration had progressed over the previous three months and was not associated with headache. Ophthalmoscopy showed normal optic discs. MRI scanning showed a large frontal basal meningioma, which was subsequently resected. Results: The patient noticed an immediate improvement in his vision in his right eye. Visual acuity in his right eye improved to 20/50 at six weeks postoperatively and to 20/25 at five months, with corresponding improvement of the visual field. Conclusion: Complete monocular blindness due to tumour compressing or distorting the anterior visual pathways does not preclude recovery following timely decompressive surgery, especially when the appearance of the optic disc is normal.

RÉSUMÉ: Régression postopératoire d'une cécité monoculaire complète chez un patient atteint d'un méningiome de la base du crâne. Contexte: Les méningiomes de la fosse antérieure se manifestent souvent par une altération de la vision. Il est important d'inclure cette entité dans le diagnostic différentiel de la neuropathie optique indolore, progressive et asymétrique, car la régression de la perte visuelle est possible si l'exérèse de la tumeur est faite à temps. Méthodes: Un patient âgé de 76 ans a consulté pour une absence de perception lumineuse au niveau de l'œil droit et une acuité visuelle réduite à 20/60 au niveau de l'œil gauche, accompagnée d'une constriction importante de son champ visuel. La détérioration de sa vision évoluait depuis trois mois et n'était pas associée à de la céphalée. L'ophtalmoscopie a montré des disques optiques normaux. À l'imagerie par résonance magnétique, on a découvert un gros méningiome basal frontal qui a été réséqué. Résultats: Le patient a constaté une amélioration immédiate de sa vision de l'œil droit. L'acuité visuelle était de 20/50 six semaines après la chirurgie et de 20/25 cinq mois plus tard, avec une amélioration correspondante du champ visuel. Conclusion: Une cécité monoculaire complète due à une tumeur comprimant ou déformant les voies visuelles antérieures peut régresser après une décompression chirurgicale précoce, surtout quand le disque optique est d'apparence normale.
\end{abstract}

Can. J. Neurol. Sci. 2003; 30: 72-74

Impairment of vision is a recognised mode of presentation of tumours of the anterior cranial fossa and suprasellar region. Visual recovery from complete loss of vision is exceedingly rare. Our review of the literature on compressive optic neuropathy and visual recovery following surgical decompression shows several reports on the incidence, severity and pathology of the compression of the anterior visual pathways. ${ }^{1-10}$ Visual recovery has also been studied but, on account of the nature and rarity of this syndrome, this has been limited to case or series reports of an observational nature, in addition to a few experimental models. . $^{13,7,9,10}$ We report the recovery of vision in the blind eye of a patient after resection of an anterior skull base meningioma.

\section{CASE REPORT}

A 76-year-old retired truck driver presented with rapidly progressing visual loss of three months duration. This he noticed to initially affect the right eye. Vision in this eye had deteriorated "to nothing" over this period, and had progressed to impair sight in his left eye as well. He had not experienced any headaches, although his symptoms included occasional episodes of dizziness and vomiting. An interesting aspect of his family history was the resection of a large tentorial meningioma from the patient's son at age 46 years, by the senior author, six years previously.

From the Divisions of Neurosurgery (JB, MB) and Neuro-Ophthalmology (PR), Toronto Western Hospital, University Health Network, University of Toronto, Toronto, Canada.

ReCEIVEd January 2, 2002. ACCEPTED In Final fORm August 28, 2002. Reprint requests to: Mark Bernstein, The Toronto Western Hospital, West Wing 4W451, 399 Bathurst Street, Toronto, Ontario, Canada M5T 2S8. 
A
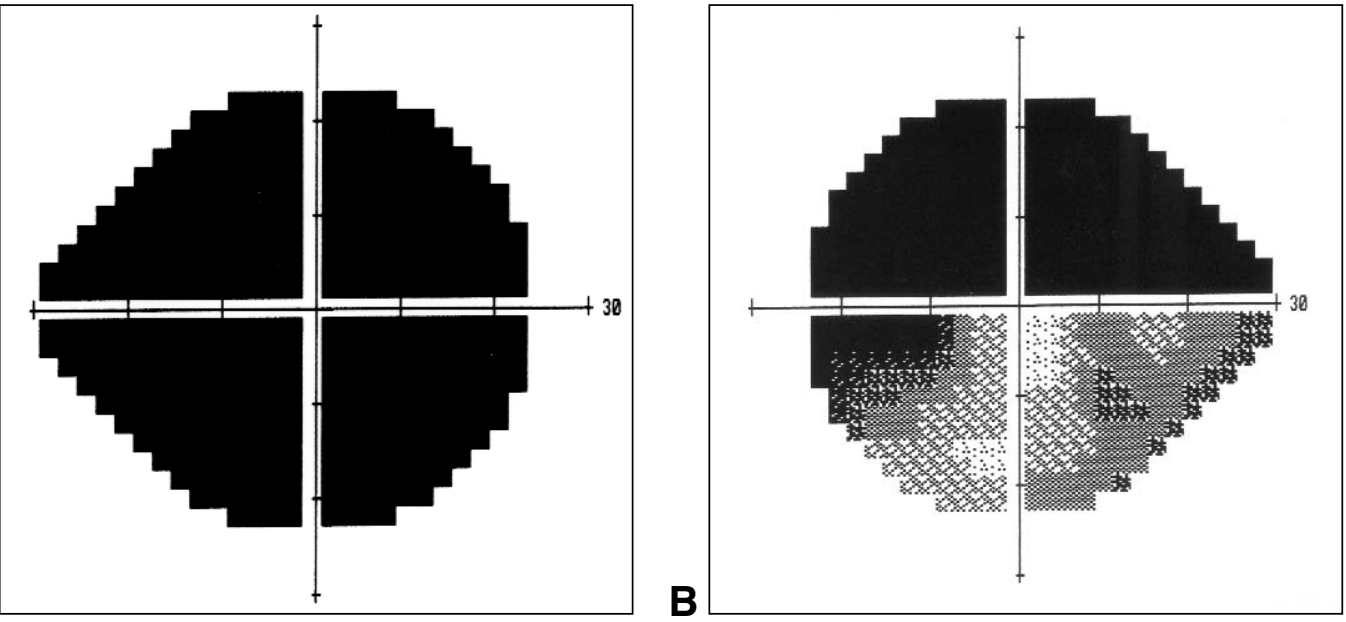

Figure 1: Humphrey central 24-2 threshold visual field test reveals

(A) complete absence in the right eye, and

(B) a dense superior altitudinal defect in the left eye, with depression of the inferior visual field.

On examination, the patient had no stigmata of neurofibromatosis. There was no light perception in his right eye. His left eye had a visual acuity of $20 / 60-1$, best corrected. The right pupillary response to direct light was absent. The left pupillary response was brisk, with a 4+ right relative afferent pupillary defect. The right eye visual field was absent to the Humphrey 24-2 test [Figure 1A]; the left eye showed a dense superior altitudinal hemianopia with depression of the inferior field. [Figure 1B]. Fundoscopy showed both optic discs to be near-normal, with perhaps slight pallor, with normal optic cups. Eye movements were full and normal. The rest of the cranial nerves were intact, as were the motor and sensory exams.

The clinical impression was that the patient had a compressive optic

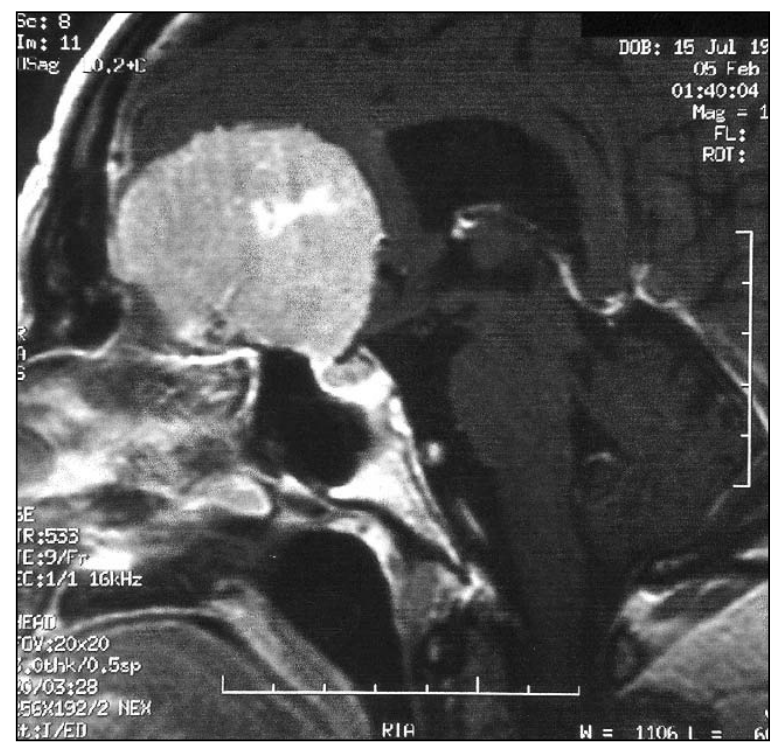

neuropathy. An MRI scan of the brain revealed a large frontal basal mass, characteristic of a meningioma with bilateral optic nerve compression. [Figure $2 \mathrm{~A}$ and $\mathrm{B}$ ].

The patient was admitted and underwent a bilateral orbitofrontal craniotomy. A large anterior skull base meningioma, probably originating from the olfactory groove or the tuberculum sellae was completely resected. The tumour had flattened the right optic nerve and was encroaching on the medial aspect of the left optic nerve. The histological diagnosis was that of a meningioma with mild nuclear atypia. Tumour architecture was maintained and no necrosis or brain invasion was seen.

The patient reported noticing an immediate restoration of vision in

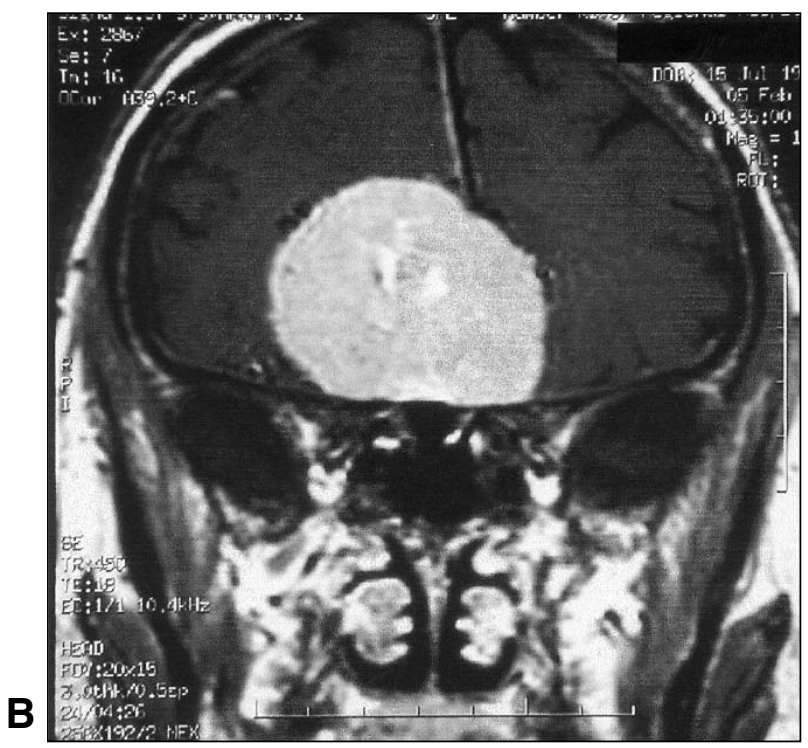

Figure 2: Sagittal (A), and coronal (B), contrast enhanced MRI scans showing a large extra-axial mass located anteriorly in the midline with it's inferior surface abutting the floor of the anterior cranial fossa The mass is well-marginated and demonstrates homogeneous enhancement following gadolinium injection. It extends on both sides of the falx, more so on the right.. The features are consistent with a meningioma demonstrating mass effect on the right frontal lobe and causing compression on the optic nerves and chiasm. 


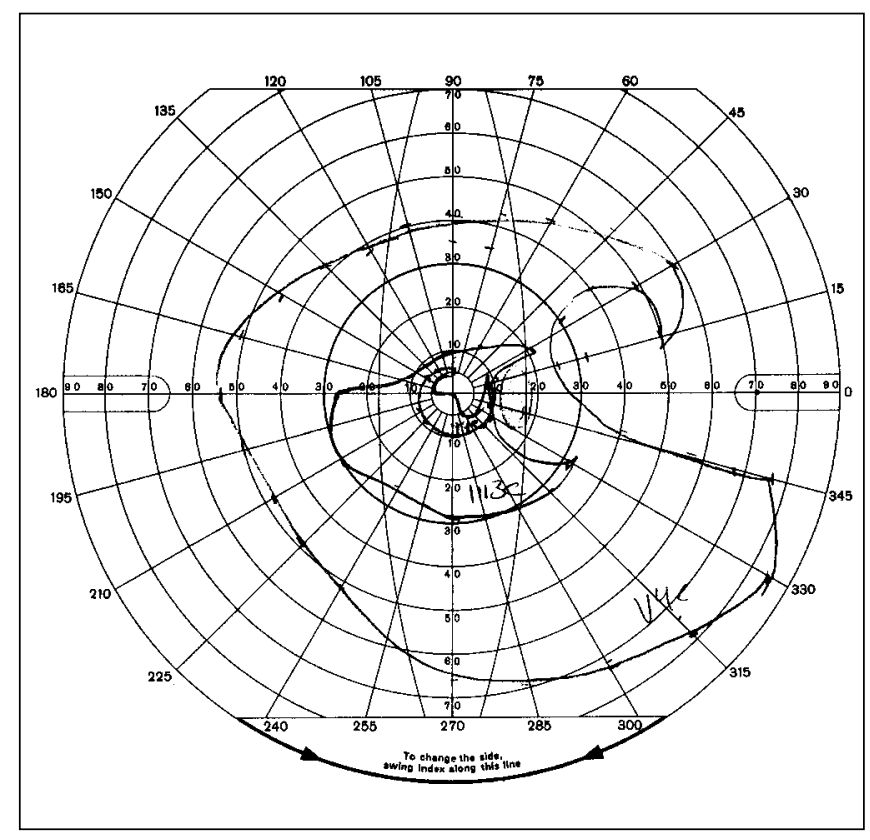

Figure 3: Goldmann visual field study reveals restoration of the entire right eye field to the large V4e target, with some residual temporal depression lateral to the normal blind spot.

his right eye in the recovery room postoperatively. He could now see clearly with this eye whereas he was "seeing black" before. Postoperative recovery was unremarkable. On oupatient review six weeks later, visual acuity of the right eye had improved to 20/40; after five months it had improved to 20/25. Subsequent visual field examination by the Goldmann method (14 weeks after surgery) [Figure 3] showed improvement of the right eye visual field, from complete absence to a moderately depressed field with a $85^{\circ}$ diameter V4e isopter.

\section{Discussion}

Recovery of useful vision after complete loss due to compressive optic neuropathy is extremely rare. Kayan and Earl ${ }^{9}$ reported the postoperative recovery of some vision in a patient who presented with rapid bilateral visual failure in three days due to pituitary infarction. Perception of light returned seven days after decompressive surgery. Visual recovery after six months was limited to hand movements in one eye and 6/60 in the other. ${ }^{9}$ Of the 11 patients who showed improvement in visual function postoperatively, in the series of 70 patients with suprasellar meningioma reported by Jallu and coworkers, ${ }^{6}$ most presented with visual function better than counting fingers. No patient with a blind eye (no light perception) showed improvement after surgery. ${ }^{6}$ In Gregorius et al's ${ }^{10}$ series of 23 patients with suprasellar meningioma, three eyes with only finger-counting vision preoperatively attained $20 / 40$ or better vision after operation. Three of the five eyes that became worse postoperatively had only 20/200 vision or less preoperatively.
Finally, in the series of 101 consecutive cases of suprasellar meningioma reported by Rosenstein and Symon, ${ }^{3}$ no patient with severe visual loss had a return of vision to normal, while $41.2 \%$ of patients with mild visual loss had the return of normal vision.

The occasional rapid recovery of vision following decompressive surgery has been noted by several investigators. ${ }^{1,9,10}$ This is followed by a later slower phase of recovery. Inferring from work on several animal models and neurophysiological recordings from patients with compressive optic neuropathy, McDonald ${ }^{1}$ has suggested that visual impairment is due to a combination of loss of nerve fibres by Wallerian degeneration, conduction block as a result of demyelination, and "physiological block" in fibres that would be able to conduct if they were not compressed. These would include histologically normal fibres and remyelinated fibres. The early rapid phase of recovery would then be due to the restoration of conduction in the latter two groups of fibres. ${ }^{1}$

The etiology of transient ("physiological") block of nerve fibres causing rapidly reversible visual loss is thought to be ischaemic. ${ }^{1,8}$ Prolonged compression (as in meningioma ) would lead to an increased tendency towards irreversibility, seen as optic atrophy on fundoscopy. Of note, Rosenstein and Symon ${ }^{3}$ found that of several factors investigated, including patient age, preoperative visual loss, duration of visual symptoms, and tumor size, the status of the optic discs at the time of admission had the strongest influence on prognosis of visual function. Of their 14 patients with normal optic discs on fundoscopic examination, 12 showed a postoperative improvement in visual function. ${ }^{3}$ The almost miraculous recovery of vision in our patient's right eye could be explained on the basis that compression of the right optic nerve had not progressed beyond the critical degree to cause irreversible ischaemia.

\section{REFERENCES}

1. McDonald WI. The symptomatology of tumours of the anterior visual pathways. Can J Neurol Sci 1981; 9:381-390.

2. Symon L, Rosenstein J. Surgical management of suprasellar meningioma. Part 1: The influence of tumor size, duration of symptoms, and microsurgery on surgical outcome in 101 consecutive cases. J Neurosurg 1984; 61:633-641.

3. Rosenstein J, Symon L. Surgical management of suprasellar meningioma. Part 2: Progonsis for visual function following craniotomy. J Neurosurg 1984; 61:642-648.

4. Page NGR, Sanders MD. Bilateral central scotomata due to intracranial tumour. Br J Ophthalmol 1984; 68:449-457.

5. Raco A, Bristot R, Domenicucci M, Cantore G. Meningiomas of the tuberculum sellae. Our experience in 69 cases surgically treated between 1973 and 1993. J Neurosurg Sci 1999; 43:253-262.

6. Jallu A, Kanaan I, Rahm B, Siqueira E. Suprasellar meningioma and blindness: a unique experience in Saudi Arabia. Surg Neurol 1996; 45:320-323.

7. Andrews BT, Wilson CB. Suprasellar meningiomas: the effect of tumor location on postoperative visual outcome. J Neurosurg 1988; 69:523-528.

8. Hilton-Jones D, Ponsford JR, Graham N. Transient visual obscurations, without papilloedema. J Neurol Neurosurg Psychiatry 1982; 45:832-834.

9. Kayan A, Earl CJ. Compressive lesions of the optic nerves and chiasm. Pattern of recovery of vision following surgical treatment. Brain 1975; 98:13-28.

10. Gregorius FK, Hepler RS, Stern WE. Loss and recovery of vision with suprasellar meningiomas. J Neurosurg 1975; 42:69-75. 